\title{
Failure of conventional chemotherapy in aggressive lymphomas
}

\author{
D. Cunningham ${ }^{1}$, A. Hepplestone ${ }^{2}$, N. L. Gilchrist ${ }^{1}$, J. H. Dagg ${ }^{2}$, I. L. Evans ${ }^{3}$ and \\ M. Soukop ${ }^{1}$
}

${ }^{1}$ Department of Medical Oncology, Royal Infirmary, Glasgow G4 OSF and Departments of ${ }^{2}$ Medicine and

${ }^{3}$ Haematology, Western Infirmary, Glasgow, UK.

\begin{abstract}
Summary: Between 1975 and 1982 in 2 centres in Glasgow, 53 previously untreated patients with aggressive non-Hodgkin's lymphomas received chemotherapy consisting of one of the following regimensCVP, MOPP, CHOP or BACOP. Twenty nine patients (55\%) entered complete remission (CR), 20 (38\%) had partial remission (PR) and 4 (7\%) had progressive disease (PD). Of the 29 patients in CR, 9 have relapsed and died, 5 died of infection, 4 died of non-malignant causes, and 11 (21\%) remain alive and disease free. The median survival for the CR group is $\mathbf{4 0}$ months. All of the patients in the PR and PD group are dead, median survival 11 months.

These chemotherapy regimens will cure only the minority of patients with aggressive lymphomas and the use of more intensive regimens is indicated.
\end{abstract}

\section{Introduction}

Aggressive non-Hodgkin's lymphomas have a very poor prognosis unless treated with chemotherapy. Combination chemotherapy regimens such as MOPP or BACOP can cure over a third of patients with diffuse histiocytic lymphoma. ${ }^{1,2}$ However, the initial promise of CHOP, which was reported to produce complete remission in almost $60 \%$ of patients with aggressive lymphomas was not realised because almost $50 \%$ of patients relapsed within the first 12 months of stopping chemotherapy. ${ }^{3}$ Further innovation and increasing the intensification of combination chemotherapy programmes have increased the proportion of patients entering complete remission and it should now be feasible to cure between $60-70 \%$ of all patients with aggressive lymphomas. ${ }^{4-6}$ However, the majority of data generated from lymphoma studies has emanated from the USA and usually from the specialized centres. ${ }^{1-6}$ Results from the United Kingdom, although confirming the ability to cure aggressive non-Hodgkin's lymphoma, have not reproduced the high response rates reported from the United States. ${ }^{7}$

The purpose of the present review was to establish the long-term outcome for patients with aggressive lymphomas receiving combination chemotherapy in the West of Scotland. The majority of data came from

Correspondence: D. Cunningham, M.B., M.R.C.P. Accepted: 3 July 1986 one centre and there was no patient selection for chemotherapy.

\section{Patients and methods}

Between January 1975 and December 1982, 41 consecutive patients from the Lymphoma Unit of the Royal Infirmary, Glasgow and 12 patients with adequate clinical records from the Western Infirmary, Glasgow received chemotherapy for aggressive nonHodgkin's lymphoma. They comprised 32 males and 21 females with a median age of 57 years (range 16-80). None of the patients had received previous chemotherapy but two patients had been given involved field radiotherapy and had relapsed. Patients were staged using routine haematological and biochemical parameters, chest radiograph, unilateral iliac crest bone biopsy and marrow aspiration. Lymphangiography or CT scanning was used to assess intraabdominal lymphadenopathy. Histology using the Rappaport classification, and staging of the patients are shown in Table I. The two patients with DPDL had lymphoblastic lymphoma. Seven patients had extranodal involvement; skin 2, bone 3 and gastrointestinal tract 2. Four different combination chemotherapy regimens were used (Table II). Patients over 70 received a $25 \%$ dose modification of therapy and chemotherapy was delayed for 5-7 days if the total white blood cell count was $<3 \times 10^{9} / 1$ or platelet 
Table I Characteristics of patients treated with chemotherapy

\begin{tabular}{|c|c|}
\hline & $\begin{array}{c}\text { Number of } \\
\text { patients }\end{array}$ \\
\hline \multicolumn{2}{|l|}{ Histology } \\
\hline Diffuse mixed (DM) & 9 \\
\hline Diffuse histiocytic (DH) & 40 \\
\hline Diffuse poorly differentiated (DPDL) & 2 \\
\hline Diffuse undifferentiated (DU) & 2 \\
\hline Total & $\overline{53}$ \\
\hline Stage & A $\mathbf{B}$ \\
\hline I & 41 \\
\hline II & $1-$ \\
\hline III & $9 \quad 11$ \\
\hline IV & 1017 \\
\hline
\end{tabular}

count was $<75 \times 10^{9} / 1$. None of the patients received prophylactic cranial irradiation or intrathecal methotrexate.

Survival was taken from the date of starting chemotherapy. Duration of complete remission was calculated from the time of documented remission using clinical assessment and any other relevant investigation, until relapse. Curves were plotted by the life table method.

\section{Results}

\section{Response to chemotherapy}

The minimum follow-up for patients in this study was 33 months, ranging to a maximum of 96 months. Complete remission (CR) was obtained in $29(55 \%)$, partial remission (PR) in $20(38 \%)$ and $4(7 \%)$ patients had progressive disease (PD) (Table III).

The median number of pulses of chemotherapy required to obtain $C R$ was four, with a range from 1-6. Of the 29 patients in CR: 17 had DH, eight had DM, two had DU and one had DPDL; four were stage I, one was stage II, 11 were stage III and 13 were stage IV; 15 had no symptoms and 14 had 'B' symptoms. Eleven $(21 \%)$ patients are alive and disease free, nine patients have relapsed and died and five patients died of infection while neutropenic but in CR. Causes of infective deaths were bronchopneumonia in three and septicaemia in two. Non-malignant causes of death in CR were: a subdural haematoma in an 80 year old patient off chemotherapy, congestive cardiac failure in a 61 year old with ischaemic heart disease, a cerebrovascular accident in a 60 year old and pulmonary embolus in a 60 year old. All of these diagnoses were confirmed at post-mortem, at which there was no evidence of lymphoma. Median time to relapse was 18 months, range 5-36 months (Figure 1). The lates

Table II Details of chemotherapy regimens

\begin{tabular}{|c|c|c|c|c|}
\hline Chemotherapy & & Days & & $\begin{array}{c}\text { Number of } \\
\text { patients }\end{array}$ \\
\hline \multicolumn{5}{|l|}{ CVP } \\
\hline Cyclophosphamide & $750 \mathrm{mg} / \mathrm{m}^{2}$ & 1 & & \\
\hline Vincristine & $1.4 \mathrm{mg} / \mathrm{m}^{2}$ & 1 & $\begin{array}{l}\text { every } \\
3 \text { weeks }\end{array}$ & 16 \\
\hline Prednisolone & & & & \\
\hline \multicolumn{5}{|l|}{ MVPP } \\
\hline Mustine & $6 \mathrm{mg} / \mathrm{m}^{2}$ & $1+8$ & & \\
\hline Vinblastine & $6 \mathrm{mg} / \mathrm{m}^{2}$ & $1+8$ & every & 16 \\
\hline Procarbazine & $100 \mathrm{mg}$ (oral) & $1-14$ & 6 weeks & \\
\hline Prednisolone & $40 \mathrm{mg}$ (oral) & $1-14$ & & \\
\hline \multicolumn{5}{|l|}{ CHOP } \\
\hline Cyclophsophamide & $750 \mathrm{mg} / \mathrm{m}^{2}$ & 1 & & \\
\hline Adriamycin & $50 \mathrm{mg} / \mathrm{m}^{2}$ & 1 & every & \\
\hline Vincristine & $1.4 \mathrm{mg} / \mathrm{m}^{2}$ & 1 & 3 weeks & 17 \\
\hline Prednisolone & $40 \mathrm{mg}$ (oral) & $1-5$ & & \\
\hline BACOP & & & & \\
\hline Cyclophosphamide & $750 \mathrm{mg} / \mathrm{m}^{2}$ & $1+7$ & & \\
\hline Adriamycin & $30 \mathrm{mg} / \mathrm{m}^{2}$ & $1+7$ & & \\
\hline Vincristine & $1.4 \mathrm{mg} / \mathrm{m}^{2}$ & $1+7$ & every & 4 \\
\hline Bleomycin & $7.5 \mathrm{mg} / \mathrm{m}^{2}$ & $1+7$ & 4 weeks & \\
\hline Prednisolone & $60 \mathrm{mg}$ (oral) & $1-14$ & & \\
\hline
\end{tabular}


Table III Response to chemotherapy, and outcome in 53 patients with aggressive lymphomas treated with chemotherapy. (Figures are numbers (\%) of patients)

\begin{tabular}{|c|c|c|c|c|c|c|c|c|c|}
\hline \multirow[b]{2}{*}{$\begin{array}{l}\text { Chemoth- } \\
\text { erpy } \\
\text { regime }\end{array}$} & \multirow[b]{2}{*}{$\begin{array}{l}\text { Number } \\
\text { of } \\
\text { patients }\end{array}$} & \multirow[b]{2}{*}{$\begin{array}{c}\text { Complete } \\
\text { remission } \\
\quad C R\end{array}$} & \multirow[b]{2}{*}{$\begin{array}{c}\text { Partial } \\
\text { remission }\end{array}$} & \multirow[b]{2}{*}{$\begin{array}{c}\text { Progressive } \\
\text { Disease }\end{array}$} & \multirow[b]{2}{*}{ Relapsed } & \multicolumn{4}{|c|}{ Cause of death in patients obtaining $C R$} \\
\hline & & & & & & $\begin{array}{c}\text { Progressive } \\
\text { disease }\end{array}$ & $\begin{array}{l}\text { Infection } \\
\text { in } C R\end{array}$ & $\begin{array}{c}\text { Non- } \\
\text { malignant } \\
\text { cause in } C R\end{array}$ & $\begin{array}{l}\text { Alive in } \\
\text { remission }\end{array}$ \\
\hline CVP & 16 & 8 & 7 & 1 & 2 & 2 & 2 & - & 4 \\
\hline MVPP & 16 & 9 & 4 & 3 & 3 & 3 & 2 & 1 & 3 \\
\hline CHOP & 17 & 9 & 8 & - & 4 & 4 & 1 & 2 & 2 \\
\hline BACOP & 4 & 3 & 1 & - & 0 & 0 & 0 & 1 & 2 \\
\hline Total & 53 & $29(55)$ & $20(38)$ & $4(7)$ & $9(17)$ & $9(17)$ & $5(9)$ & $4(7)$ & $11(21)$ \\
\hline
\end{tabular}

relapse, which occurred at 56 months, was a solitary central nervous system relapse in a patient with DU lymphoma. An ommaya reservoir was used to administer intrathecal methotrexate but the patient died. All other relapses were at the site of maximum disease at presentation.

All of the patients who had a PR or PD following chemotherapy are dead. For the 29 patients who entered CR the median survival is $\mathbf{4 0}$ months (Figure 2 ). Of the 11 patients who are long-term survivors; nine had DH and two had DM lymphomas; three patients were stage I, one was stage II and seven were stages III or IV at presentation. When analysed using the chi-square test, histology or the presence of constitutional symptoms had no significant effect on long-term survival, whereas, patients with stage I or II disease survived significantly longer $(P<0.01)$. Seven of the long-term surviving patients received chemotherapy without Adriamycin but four of these patients had stage I or II disease and when these patients are excluded survival for each chemotherapy group is similar.

The most frequent toxicity was myelosuppression. The median total white blood count nadir was $1.7 \times 10^{9} / 1$, range $0.5-6.9 \times 10^{9} / 1$ and the median nadir platelet count was $144 \times 10^{9} / 1$ (range $11-374 \times 10^{9} / 1$ ).

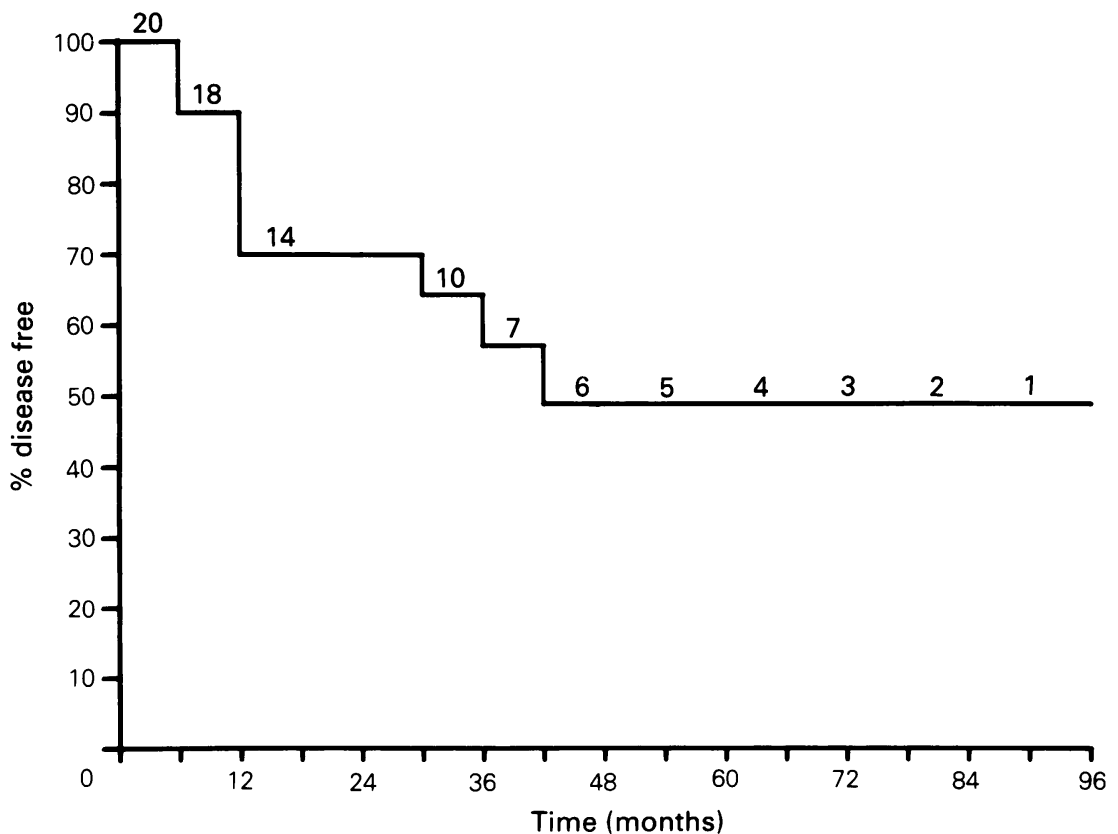

Figure 1 Time to relapse for 20 patients achieving complete remission, excluding those patients who died of causes other than lymphoma whilst in complete remission. 


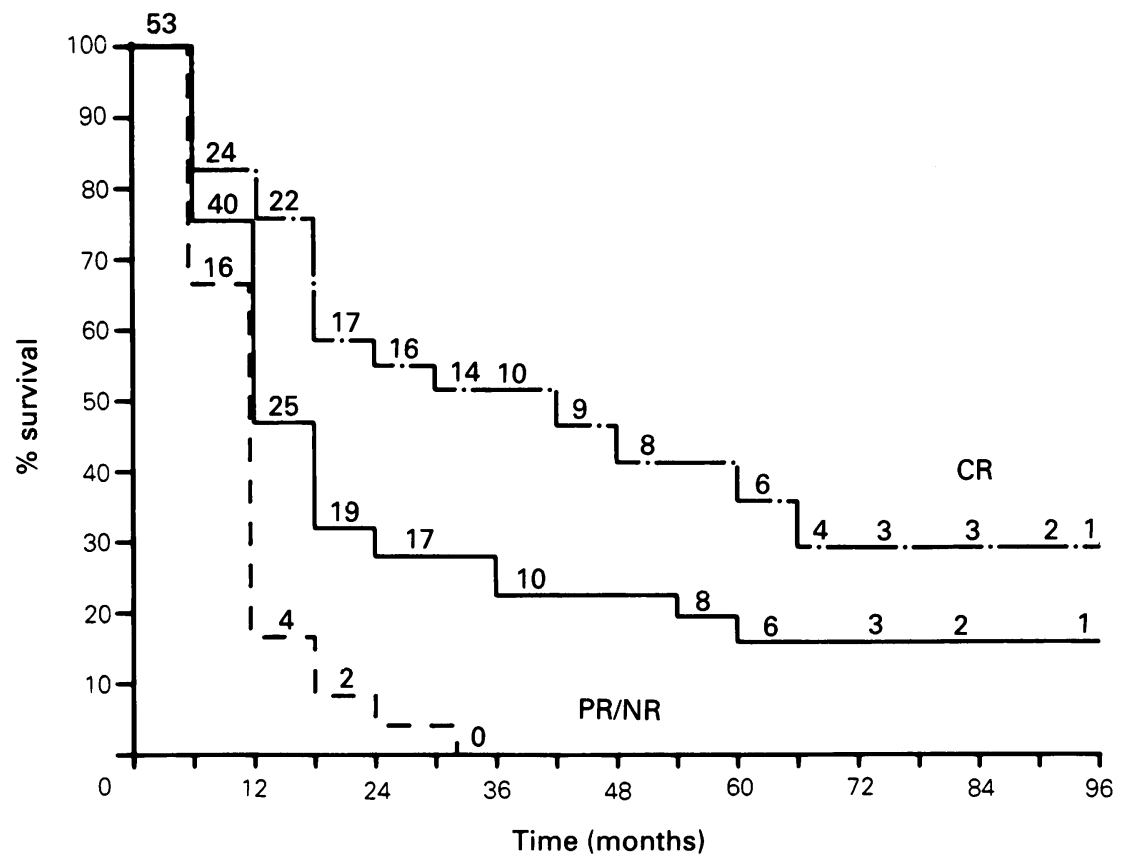

Figure 2 Survival of patients according to response to chemotherapy.

Six patients $(11 \%)$ developed platelet counts of $<50 \times 10^{9} / 1$ but only two patients required platelet transfusions and there were no haemorrhagic deaths. All patients receiving adriamycin-containing combinations and four patients $(29 \%)$ receiving CVP developed complete alopecia. There was no hair loss with MVPP. Neurotoxicity was only encountered with the regimens containing vincristine, characterized by mild paraesthesia which was common $(68 \%)$, but there were no serious neurological sequelae. It is not possible to comment on the emetogenicity of these regimens; a variety of anti-emetics were used and there was no formal documentation of nausea and vomiting after chemotherapy.

\section{Discussion}

The results of this long-term follow-up study of patients with aggressive non-Hodgkin's lymphoma receiving moderately intensive chemotherapy regimens have shown that only one fifth of patients have the prospect of being cured of their disease. Indeed, if patients with stage I or stage II disease are excluded the results are even more dismal, with only $15 \%$ of patients with advanced disease enjoying prolonged disease-free survival. These results contrast sharply with the American experience even when compared with studies using identical chemotherapy regimens. This is rather surprising since our patient population, stage of disease and histology were equivalent to those in the American studies - apart from the NCI ProMACE-MOPP Programme in which the median age of patients entered into the study was 44 years, which is considerably younger than our patients and may have favourably affected their outcome. ${ }^{4}$

Our findings are similar to that reported by the St Bartholomew's hospital group ${ }^{7}$ - they found that only $25 \%$ of patients with aggressive lymphomas were disease-free 3-8 years after receiving chemotherapy consisting of adriamycin, vincristine, prednisolone and L-asparaginase, with maintenance methotrexate, cyclophosphamide and 6-mercaptopurine. Nonetheless, one area in which our results could have been improved is in relation to the number of infective deaths which occurred whilst patients were in complete remission. Whereas, one must expect an induction mortality rate for intensive chemotherapy re- No gimens, ${ }^{4}$ we consider that the $17 \%$ mortality rate among our patients achieving complete remission was unacceptably high. Indeed, the high mortality rate in our study probably reflected the lack of intensive support facilities in one centre (Glasgow Royal Infirmary) during the first 5 years of the study.

The small number of patients in this study did not permit an extensive analysis of each individual his- 
tological subgroup. However, it is now clear that the term 'aggressive lymphoma' embraces a' heterogeneous group of tumours, ${ }^{8}$ and that some tumours such as lymphoblastic lymphoma ${ }^{9}$ demand more intensive chemotherapy than others. We used the Rappaport classification of non-Hodgkin's lymphoma to present our histological data because this was the usual classification used by our pathologists during the time studied, and also because it allowed us to compare the results with currently published literature. However, we accept that the use of this classification is now likely to be superseded by the more modern classifications which take account of the advances made in the immunocytochemical classification of lymphoma. ${ }^{10}$ Nevertheless, this does not invalidate our results since

\section{References}

1. Devita, V.T. Jr., Canellos, G.P., Chabner, B.A., Schein, P, Hubbard, S.P. \& Young, R.C. Advanced diffuse histiocytic lymphoma, a potentially curable disease: results with combination chemotherapy. Lancet 1975, i: 248-250.

2. Skarin, A.T., Rosenthal, D.S., Maloney, W.C. \& Frei, E., III. Combination chemotherapy of advanced non-Hodgkin's lymphoma with bleomycin, adriamycin, cyclophosphamide, vincristine and prednisolone (BACOP). Blood 1977, 49: 759-770.

3. Jones, S.E., Crozea, P.N., Metz, E.N. et al. Superiority of adriamycin containing combination chemotherapy in the treatment of diffuse lymphoma: a Southwest Oncology Group Study. Cancer 1979, 43: 417-425.

4. Fisher, R.I., Devita, V.T., Jr., Hubbard, S.M., Longo, D.L., Wesley, R., Chabner, B.A. \& Young, R.C. Diffuse aggressive lymphomas: increased survival after alternative flexible sequences of ProMACE and MOPP chemotherapy. Ann Intern Med 1983, 98: 304-309.

5. Skarin, A.T., Canellos, G.P. \& Rosenthal, D.S. et al. Improved prognosis in diffuse histiocytic and undifferentiated lymphoma by use of high-dose methotrexate alter- the main purpose of this study was to present the longterm survival of a relatively unselected group of patients with aggressive lymphomas, treated with what would still be regarded as standard chemotherapy.

In conclusion, it is obvious that regimens such as MOPP or CHOP will cure the minority of patients with aggressive lymphomas and that the use of more intensive regimens is indicated, with the caveat that the appropriate supportive facilities are available.

\section{Acknowledgement}

D.C. and A.H. were funded by the Cancer Research Campaign.

nating with standared agents (M-BACOD). J Clin Oncol 1983, 1: $91-98$.

6. Laurence, J.J., Coleman, M., Allen, S.L., Silver, R.T. \& Passmantier, M. Combination chemotherapy in advanced diffuse histiocytic lymphoma with the six-drug COPBLAM regimen. Ann Intern Med 1982, 97: 190.

7. Gallagher, C.J., Copplestone, A., Meikle, J.D. \& Lister, T.A. Treatment of disseminated non-Hodgkin's lymphoma of unfavourable histology. Cancer Chemother Pharmacol 1982, 8: 237-241.

8. Non-Hodgkin's Lymphoma Pathological Classification Project. National Cancer Institute sponsored study of classifications of non-Hodgkin's lymphomas: summary and description of a working formulation for clinical usage. Cancer 1982, 49: 2112-2135.

9. Levine, A.M., Forman, S.J. \& Meyer, P.R. et al. Successful therapy of convoluted T-lymphoblastic lymphoma in the adult. Blood 1983, 61: 92-98.

10. Lukes, R.J. \& Collins, R.D. Immunological characterization of human malignant lymphomas. Cancer 1974, 34: 1488-1503. 